
\title{
$\angle$ Research Square \\ Lymphoblastic lymphoma in two young siblings (coincidence or genetics?): a case report
}

Naya Talal Hassan ( $\square$ naya.hassan97@gmail.com )

Tishreen University https://orcid.org/0000-0003-3833-8130

\section{Ebrahim Makhoul}

Tishreen University

\section{Jaafar Sallameh}

Tishreen University

\section{Abdulmunem Ghanem}

Tishreen University

\section{Samer Rajab}

Tishreen University

\section{Waseem Ali}

Tishreen University

\section{Zuheir Alshehabi}

Tishreen University

\section{Research Article}

Keywords: Lymphoblastic Lymphoma, Non-Hodgkin Lymphoma, Familial Cancer, Mediastinal Mass, Case Report.

Posted Date: May 3rd, 2021

DOI: https://doi.org/10.21203/rs.3.rs-352897/v1

License: (c) (1) This work is licensed under a Creative Commons Attribution 4.0 International License. Read Full License

Version of Record: A version of this preprint was published at Journal of Medical Case Reports on July 28th, 2021. See the published version at https://doi.org/10.1186/s13256-021-02977-1. 


\section{Abstract}

Background: Non-Hodgkin lymphoma is the fourth most common malignancy in children and it is not considered to be a hereditary disorder. However, it could affect members from the same family.

Case presentation: We are presenting two cases of Caucasian female siblings who were diagnosed with mediastinal lymphoblastic lymphoma in the same year. The two young females were presented to the emergency department with respiratory symptoms. After doing radiological investigations and biopsies, the diagnosis of lymphoblastic lymphoma was done. The elder sister died before confirming the diagnosis, and the other one is on chemotherapy now and the treatment outcomes is good.

Conclusions: This case emphasize the crucial role of precursor genetics in lymphoblastic lymphomas and suggesting the strong relation between those genetics and the age of symptoms presentation. This is the first report of non-Hodgkin siblings pair in the pediatric population.

\section{Background}

Among the homogeneous neoplasms, there are major changes that impact how these cases should be evaluated and diagnosed that have significant therapeutic effects as well as being of biologic interest (1). Non-Hodgkin lymphoma (NHL) is the fourth most common malignancy in children (2). It is not considered to be a hereditary disorder, but the occurrence of $\mathrm{NHL}$ lymphoma in the same family is called familial NHL (3). Pediatric NHL shows important differences in the distribution of histologic subtypes to $\mathrm{NHL}$ noticed in adults who have clinical characteristics represented by almost exclusively diffuse highgrade lymphomas and frequent extra nodal involvement (4). The prognosis for children with non-Hodgkin lymphoma has been getting better over the last 2 decades (5).

Here we are presenting a rare case of pediatric lymphoblastic lymphoma in two sisters; to emphasize the role of precursor genetics in lymphoblastic lymphomas and suggesting the strong relation between those genetics and the age of symptoms presentation.

\section{Case Presentation}

\section{Case 1:}

A 5-year-old Caucasian female presented to our hospital with an intense dry cough and dysphagia two weeks before the visit with no other symptoms. Her personal history was free of diseases. She was born the second of her siblings by third-degree relative parents. The clinical examination revealed small enlarged lymph nodes at the level of the neck and immobile mass at the level of her right axillary with light edema. There were diffused Café au Lait spots all over her body and pulmonary wheeze sounds with a mid-systolic murmur $2 / 6$. The rest of the examination was within normal limits. Her weight (W): $20 \mathrm{~kg}$ and her height $(\mathrm{H}): 110 \mathrm{~cm}$. Complete cellular blood count $(\mathrm{CBC})$ was completely normal. Chest X-Ray (CXR) showed a mass in the mediastinum that led to do a chest computed tomography (CT). Chest CT 
revealed a big mass along the mediastinum (Figure 1). She underwent a surgical biopsy. The histological results (Figure 2) revealed T-cell lymphoblastic lymphoma, the malignant lymphocytes showed positivity for CD3 and terminal deoxynucleotidyl transferase (TdT), whereas, CD20, myogenin, cytokeratins (CK), epithelial membrane antigen (EMA), desmin, WT1 were negative. Ki67 was 50\%. The girl went into a coma during the resection surgery and stayed in the intensive care unit (ICU) for 10 days, then, died due to cardiac arrest. We suggest that the fatal reason is the compression on the air track by the mass after the anesthesia.

\section{Case 2:}

An 18-month-old Caucasian female was admitted to a private clinic with a productive cough that was diagnosed mistakenly as bronchitis. Based on that diagnosis she took many medications (antibiotics and pain relievers) and got improved partially. She came to our hospital because of the increasing dyspnea. Her personal history was free of diseases. She was born the third of her siblings by third-degree relative parents. The clinical exam revealed the following elements: diffused Café au Lait spots all over her body and congenital Mongolian spots with enlarged submaxillary lymph nodes without any palpable visceral enlargement. Chest auscultation revealed diffuse pulmonary crackles. The rest of the examination, laboratory tests, brain CT and bone marrow biopsy were all within normal limits. Her weight (W): $10 \mathrm{~kg}$ and her height $(\mathrm{H}): 78 \mathrm{~cm}$ with head circumference: $48 \mathrm{~cm}$. Complete cellular blood count (CBC) was completely normal. Computed tomography (CT) revealed an enlarged palatine tonsil and enlarging in the mastoid lymph nodes and submaxillary lymph nodes. The nodes measured no more $11 \mathrm{~mm}$. CT also showed a mass in the mediastinum (Figure 3). In addition, there was a hyperplasia in the thymus area extending to the front of the heart. Mild hepatomegaly and enlarged paraaortic lymph nodes were found. The histological results (Figure 4) revealed T-cell lymphoblastic lymphoma with positivity for CD3 and TDT , whereas, CD20, myogenin, CK, EMA, Desmin, WT1 were negative. Ki67 was 50\%. The girl has been undergoing chemotherapy (cytarabine, vincristine, ifosfamide) till now and she is getting well, with no respiratory symptoms.

\section{Discussion And Conclusions}

It is estimated that $2 \%$ of $(\mathrm{NHL})$ cases are familial. This risk of lymphoma occuring in the same family members varies depending on multiple factors including histopathological type, age at diagnosing, sex, and familial relationship (3). It is found that male relatives are affected more than females (6).The incidence of $\mathrm{NHL}$ in siblings has been noticed for a long time, it is found that the lifetime cumulative risk of $\mathrm{NHL}$ in siblings of a patient with $\mathrm{NHL}$ was $1.6 \%$. The lifetime risk was higher when NHL was diagnosed in a sister than a brother (3). Most of the common histopathological types of NHL showed to have a familial incidence. Very high familial risk of histological subtypes were found for lymphoplasmacytic, mantle cell and cutaneous T-cell lymphomas (3). In the literature review, we found multiple cases of siblings with $\mathrm{NHL}$ (some are as case reports and others included in cross-sectional and other research studies). In 2006 Loves et al. reported a family in which three male siblings developed NHL (7). Those three siblings had different pathological types of lymphoma and were diagnosed at ages $(45,56,52)$. 
Primary gastric NHL, which occurred in two sisters and their father, were also reported by Hayoz et al. in 1993 (8). The ages of two sisters at diagnosis were $(53,46)$ and their father's age was $(78)$. Their family had no history of immunodeficiency or cancer. To our knowledge, our case is considered to be the first report of lymphoblastic lymphoma siblings pair in the pediatric population. Some studies found that the diagnosing interval for $\mathrm{NHL/NHL}$ sibling pairs is about $1-4$ years (9). In our case the interval between the appearance of symptoms in the two sisters was very short (less than one year). It is estimated that mediastinal non-Hodgkin lymphomas represent about $5 \%$ of all non-Hodgkin lymphomas. Mediastinal lymphomas can cause symptoms like fever, malaise, chest pain or other symptoms related to compression of adjacent mediastinal structures, however, it might be asymptomatic (10). Besides the site of tumor, the symptoms and the immune stains were totally similar in the two cases. The occurrence of the disease in the same family leads to many questions about sharable factors that family members could have. These factors may include genetic factors such as tumor formation in Li-Fraumeni syndrome, or immune deficiency disorders -which are very rare-. Another important factors are environmental factors such as virus infections like EBV, HIV, CMV or chemicals poisoning and pollution. The two girls have one older sister who is healthy. In our case the parents are third-degree relatives, and both of the two girls have more than 6 café au lait spots. Although there was no family history of genetic disorders and the girls were previously healthy before $\mathrm{NHL}$ diagnosing, the occurrence of the disease at the same time in the same site, at this very young age and the presence of the same skin disorders in the two patients may refer to genetic disorders. The two patients in our case did not undergo genetic testing because these tests are not available at this time in our hospital. We suggest that the familial occurrence of the disease might trigger lymphoma formation at a younger age, in unusual sites. However, the prognosis of the disease appears to be the same in familial and non-familial cases. The genetic factors are one of the most important factors that affect NHL formation. Although we don't suggest doing scanning of the patient's siblings when diagnosing $\mathrm{NHL}$, we believe that more research should be done to know the exact mechanism of how genetics are responsible for lymphoma formation in siblings and how this would affect the diagnosis and treatment of the disease.

\section{List Of Abbreviations}

NHL: Non-Hodgkin lymphoma.

CBC: Complete blood count.

CXR: Chest X-ray.

CT: Computed tomography.

TdT: Terminal deoxynucleotidyl transferase

CK: Cytokeratins.

EMA: Epithelial membrane antigen. 
ICU: Intensive care unit.

EBV: Epstein-Barr virus.

HIV: Human immunodeficiency virus.

CMV: Cytomegalovirus.

\section{Declarations}

Ethical Approval: This case report did not require review by the Ethics Committee of Tishreen University Hospital, Latakia, Syria.

Consent: Written informed consent was obtained from the patients' father for publication of this case report and any accompanying images. A copy of the written consent is available for review by the editor.

Availability of data and materials: Data mentioned in this case report are available to the reviewers if required.

Competing interests: The authors declare that they have no competing interests.

Funding: No funding was obtained for this study.

Author contributions: $\mathrm{NH}$ and EM wrote the paper. JS wrote case presentation. $\mathrm{NH}$ managed the team. ZA proofread and edited the manuscript. AG, SR and WA provided patient's data and revised the manuscript. $\mathrm{NH}$ is the corresponding author. All authors of this paper have read and approved the final version submitted.

Acknowledgments: Not applicable.

\section{References}

1. Swerdlow SH, Campo E, Pileri SA, Harris NL, Stein H, Siebert R, et al. The 2016 revision of the World Health Organization classification of lymphoid neoplasms. Blood. 2016;127(20):2375-90. doi: 10.1182/blood-2016-01-643569.

2. Minard-Colin V, Brugières L, Reiter A, Cairo MS, Gross TG, Woessmann W et al. Non-Hodgkin Lymphoma in Children and Adolescents: Progress Through Effective Collaboration, Current Knowledge, and Challenges Ahead. J Clin Oncol. 2015;33(27):2963-2974. doi:10.1200/JCO.2014.59.5827

3. Fallah M, Kharazmi E, Pukkala E, Tretli S, Olsen JH, Tryggvadottir L, et al. Familial risk of nonHodgkin lymphoma by sex, relationship, age at diagnosis and histology: a joint study from five Nordic countries. Leukemia. 2016;30(2):373-378. doi:10.1038/leu.2015.272 
4. Minard-Colin V, Brugières L, Reiter A, Cairo MS, Gross TG, Woessmann W,et al. . Non-Hodgkin Lymphoma in Children and Adolescents: Progress Through Effective Collaboration, Current Knowledge, and Challenges Ahead. J Clin Oncol. 2015;33(27):2963-74. doi: 10.1200/JCO.2014.59.5827.

5. Shiramizu B, Mussolin L, Woessmann W, Klapper W. Paediatric non-Hodgkin lymphoma perspectives in translational biology. Br J Haematol. 2016;173(4):617-624. doi:10.1111/bjh.14009

6. Chatterjee N, Hartge P, Cerhan JR, Cozen W, Davis S, Ishibe N, et al. Risk of non-Hodgkin's lymphoma and family history of lymphatic, hematologic, and other cancers. Cancer Epidemiol Biomarkers Prev. 2004;13(9):1415-1421.

7. Loves SS, de Haan L, Daenen SM. Familial Aggregation of Non-Hodgkin's Lymphoma (NHL). A Case Report. Hered Cancer Clin Pract. 2006;4(3):136-139. Published 2006 Aug 15. doi:10.1186/1897-42874-3-136

8. Hayoz D, Extermann M, Odermatt BF, Pugin P, Regamey C, Knecht H. Familial primary gastric lymphoma. Gut. 1993;34(1):136-40. doi: 10.1136/gut.34.1.136.

9. Paltiel O, Schmit T, Adler B, Rachmilevitz EA, Polliack A, Cohen A, et al. The incidence of lymphoma in first-degree relatives of patients with Hodgkin disease and non-Hodgkin lymphoma: results and limitations of a registry-linked study. Cancer. 2000;88(10):2357-2366.

10. Piña-Oviedo S, Moran CA. Primary Mediastinal Nodal and Extranodal Non-Hodgkin Lymphomas: Current Concepts, Historical Evolution, and Useful Diagnostic Approach: Part 2. Adv Anat Pathol. 2019;26(6):371-389. doi:10.1097/PAP.0000000000000248

\section{Figures}




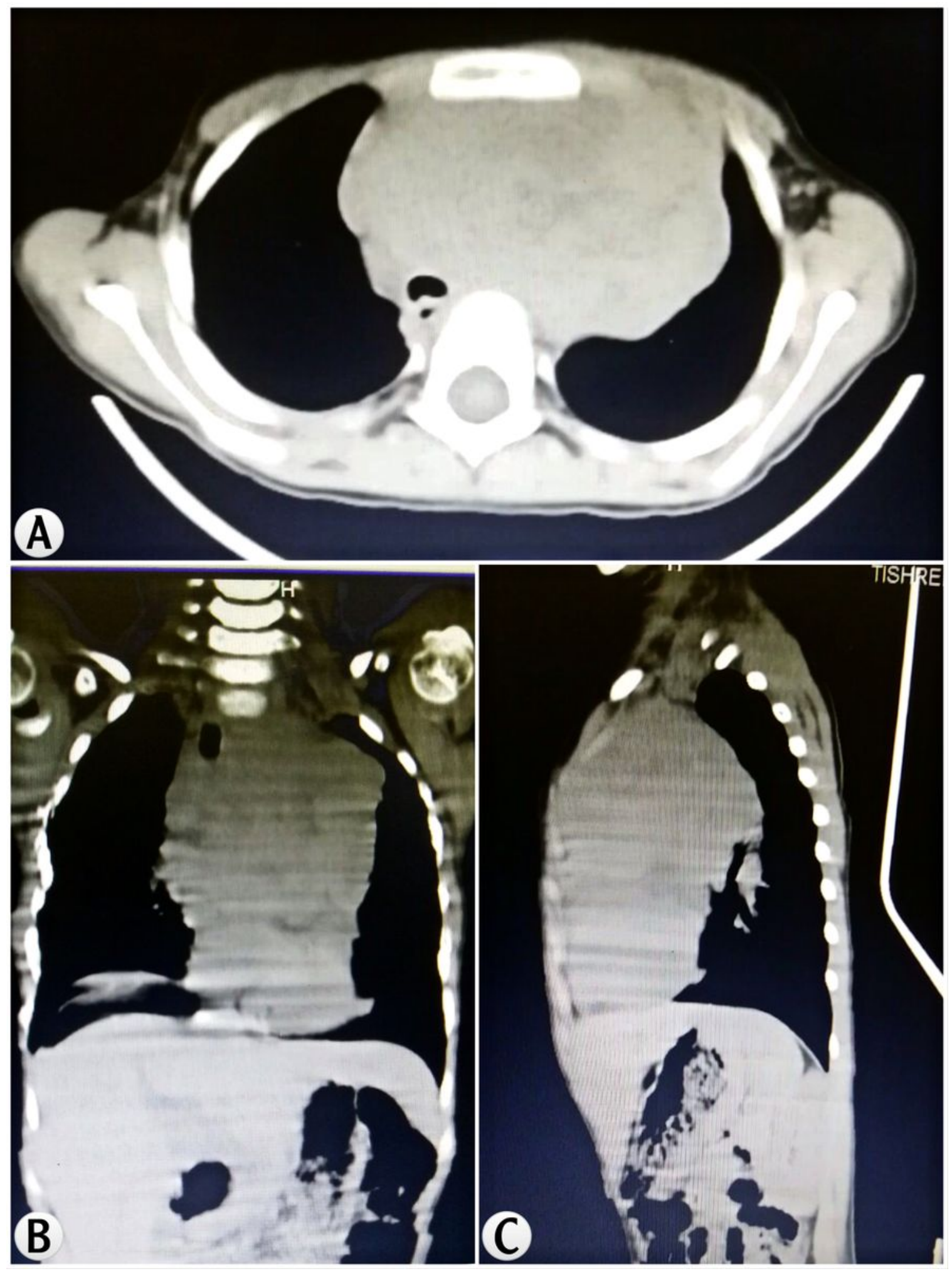

Figure 1

CT findings in case 1: The axial (A), coronal (B) and sagittal (C) CT planes show mediastinal expansion due to the big tumor mass, which is going up and out through the thoracic outlet, pushing the trachea to the right narrowing the left bronchus. 


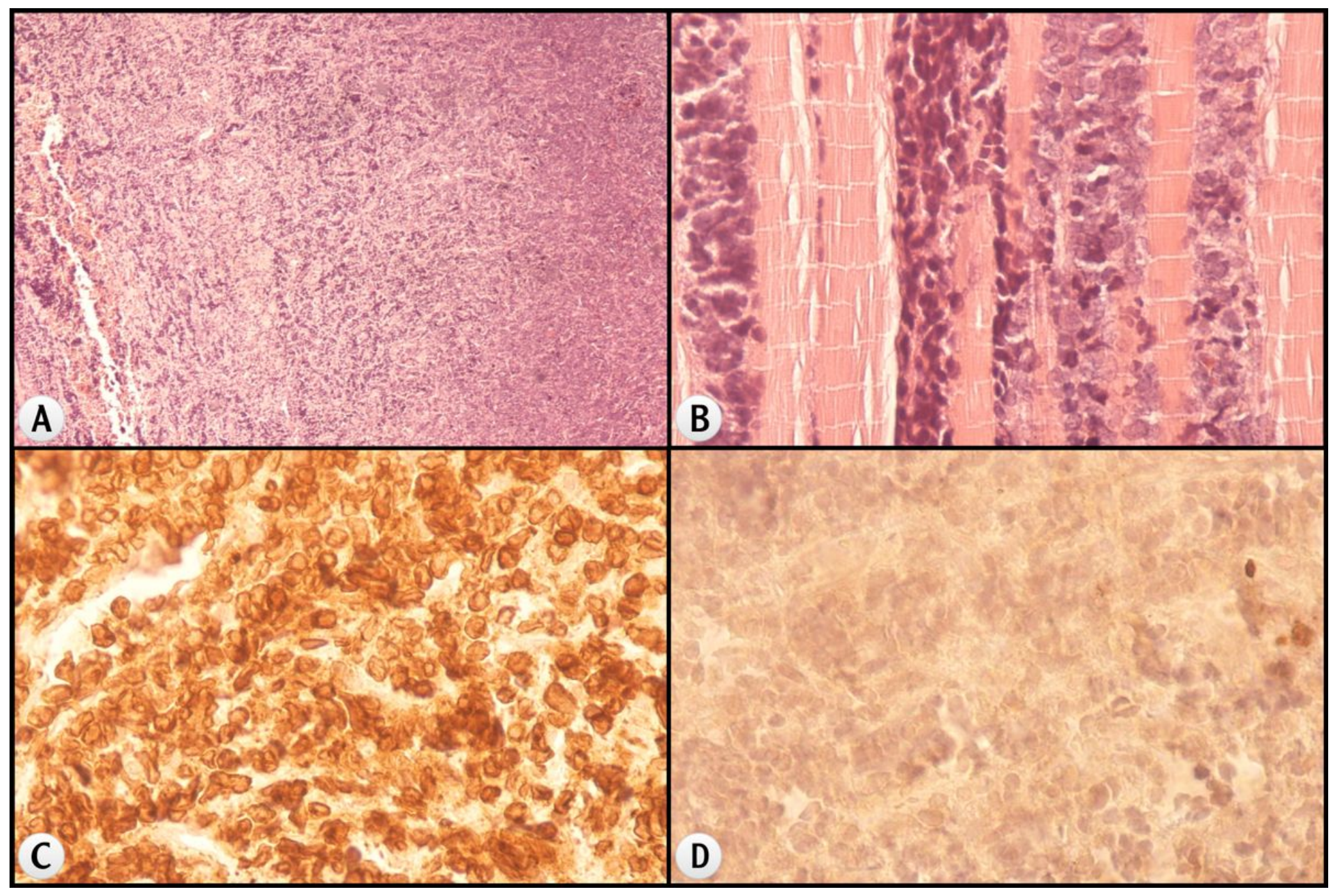

Figure 2

Histological findings of the mediastinal mass in case 1 (Surgical biopsy): The histological features of the mediastinal mass revealed $(A)(H \& E, \times 40)$ T-cell lymphoblastic lymphoma. The malignant lymphocytes invade the strained muscle tissue (B) (H\&E stain, $\times 40)$. Tumor cells shows positivity for CD3 (C) and negativity for EMA (D). 


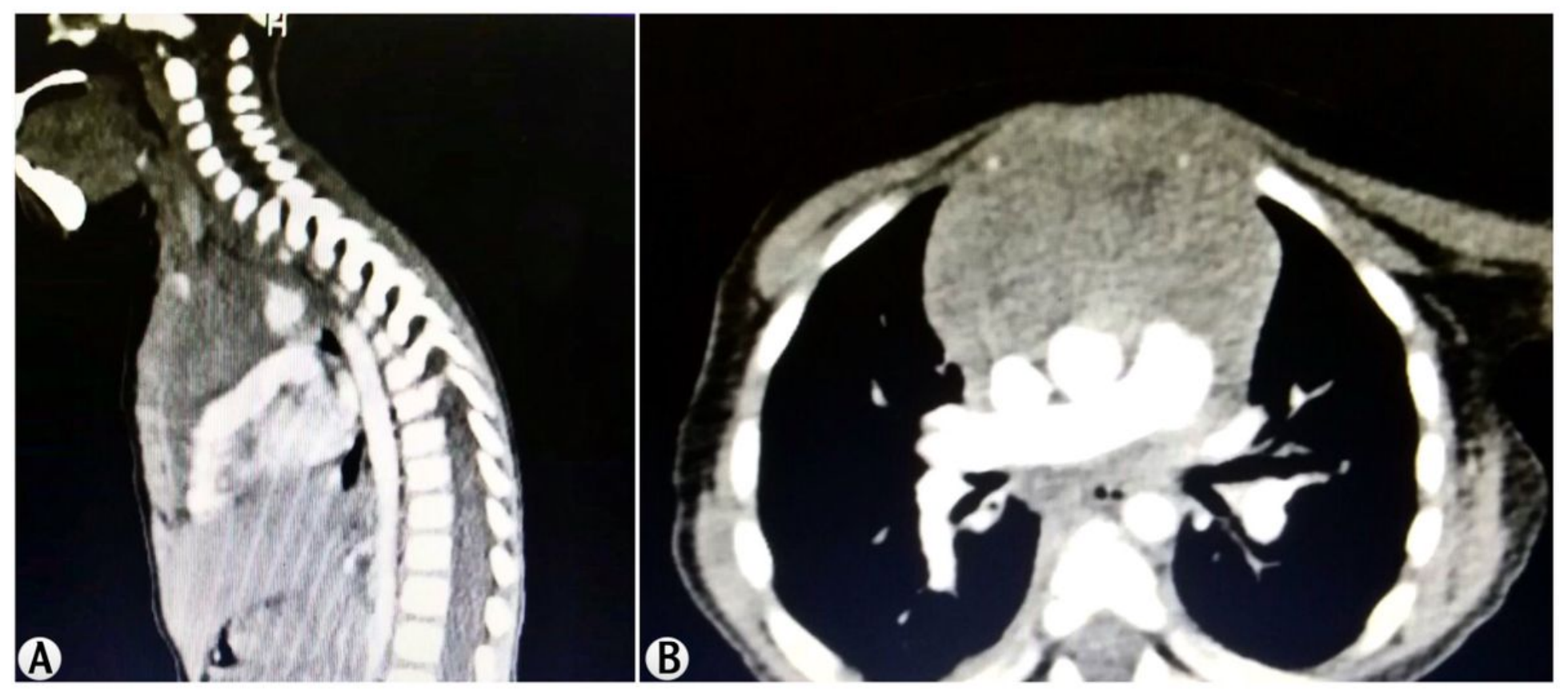

\section{Figure 3}

CT findings in case 2: The axial (A) and sagittal (B) CT planes show a large mediastinal mass rounding the neck vessels measuring $53 \times 38 \mathrm{~mm}$, extending to the thoracic cave around the branching of bronchi measuring $30 \times 29 \mathrm{~mm}$ compressing the both bronchi. 


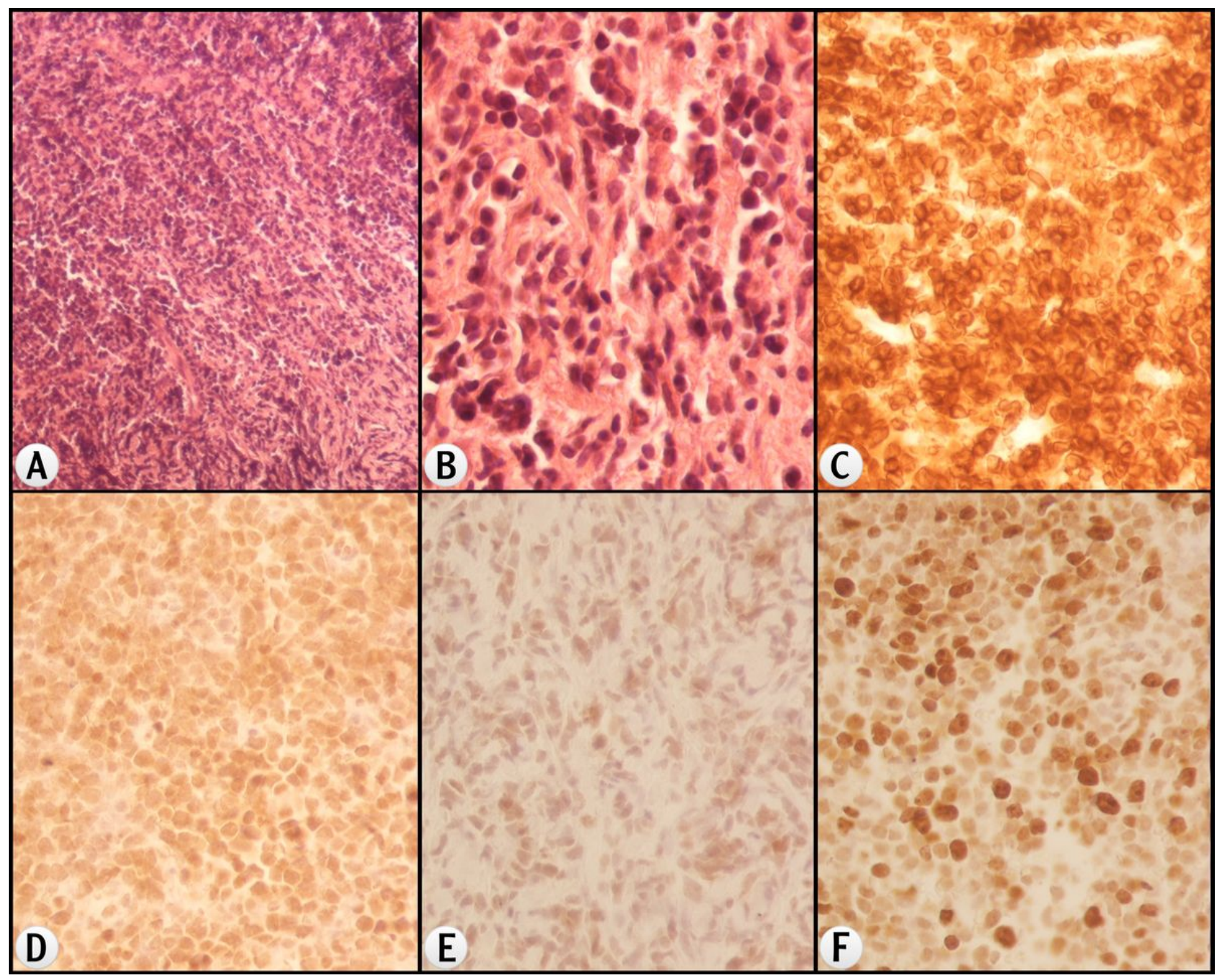

Figure 4

Histological findings of the mediastinal mass in case 2 (Fine-needle biopsy): (A) (H\&E, $\times 100)$ and $B(H \& E$, $\times 600$ ) shows the malignant lymphocytes, which are CD3 (C) and TdT (D) positive, WT1 (E) negative. Ki67 is $50 \%(\mathrm{~F})$.

\section{Supplementary Files}

This is a list of supplementary files associated with this preprint. Click to download.

- CAREchecklistEnglish2013.pdf 